\title{
Alternatives for Maintaining the Viability of the Enterprise in Post-Crisis Phase
}

\author{
Prof. PhD Tzveta Zafirova \\ University of Economics - Varna, Varna, Bulgaria \\ tzveta_zafirova@ue-varna.bg \\ Prof. PhD Margarita Bachvarova \\ University of Economics - Varna, Varna, Bulgaria \\ bachvarova@ue-varna.bg
}

\begin{abstract}
The purpose of this article is to investigate the alternatives for getting out of the crisis in each enterprise to maintain its viability. Different approaches in the specialized literature in the field of management are explored. The legal aspects of these alternatives and good international practices in the field have been explored. A sufficient number of literature sources describing the theory and practice of organizational crises have been studied and systematized. The results will help business management to make the right choice to overcome the crisis.
\end{abstract}

Key words: crisis, bankruptcy, insolvency, reorganization, liquidation, viability

JEL Code: M100, G330; doi:10.36997/IJUSV-ESS/2019.8.3.72

\section{Въведение}

Всяко предприятие в своето развитие достига до кризисни състояния. Някои от тях водят до негативни последици, други създават възможност за ново начало. След всяка криза у стейкхолдерите се появява желанието да се премине възможно най-бързо към следващ етап, за да се възобнови дейността на предприятието. То се съпътства от бизнес оздравителни програми, които се фокусират върху различни промени в него. Много модели на управление на кризи представят понятията „следкризисни” и „оздравителни” като синоними, въпреки че съществуват и становища, че изходът е винаги негативен. Но факт е, че рисковете за предприятията след кризата могат да бъдат дори по-големи, отколкото по време на нея. Това налага да се търсят възможности за снижаването им чрез тяхното оздравяване. Целта на статията е да се проучат различни световни практики за следкризисния етап на предприятията, както и правните модели за нормативната база, свързана с тях.

За целите на статията са проучени голям брой специализирана литература на учени, правни системи и нормативни актове на развити икономически държави с практика в областта, официални документи на Европейската комисия и др. Резултатите от изследванията на S. Fink, D. Smith, I.I. Mitroff, T. W. Coombs, M.W. Seeger, T.L. Sellnow \& R.R. Ulmer, Dr. Dubrovski, A. Evseev и др. върху жизнения цикъл на кризите в предприятията са използвани за теоретична основа при определяне на етапите им - precrisis, crisis and postcrisis, като е акцентирано върху становищата за следкризисния етап. В него, според посочените изследвания, има два изхода - ликвидация или оцеляване, последващо от оздравяване (Zafirova и Yordanova, 2016). При ликвидацията, която е придружена от външна намеса, също има две възможности - продажба или фалит (невъзможност на предприятието да осъществява дейността си и да извършва операции), или на практика следкризисният етап може да се развие по различен начин, който зависи от много фактори.

В изследването е възприета тезата, че управлението на предприятието в следкризисния етап трябва да акцентира върху оздравяването си чрез ликвидиране на последствията от кризата с цел то да възвърне своята жизнеспособност, като се стреми да достигне поне нивото на показателите си от предкризисния етап.

Използваните методи на анализ, синтез и сравнението са добра база за теоретични 
изводи и обобщения за необходимостта от оздравяване в следкризисния етап в управлението на предприятието като алтернатива на фалита или продажбата.

\section{1. Алтернативи за функционирането на предприятието в следкризисния етап: подходи и етапи}

Синтезирането на различни изследвания за организационните кризи ни показва, че те се разделят на три подхода от гледна точка на възприемането им, които са изследвани от Hwang и Lichtenthal (1999):

a) Ад хок подход, който разглежда кризата на парче като случаи ориентирани към перспективата им.

б) На основата на разработени типологии на кризи в резултат на класифицирането им в отделни категории на базата на наблюдения на техните прилики.

в) В зависимост от тълкуването в дефинициите за криза, които се съсредоточават върху характеристики, които представляват една кризисна ситуация.

Hwang \& Lichtenthal (1999) предлагат в своите изследвания, проучвайки посочените съществуващи подходи, съвсем друг подход в теорията на организационни кризи, свързан с равновесието, който отговаря на динамиката на еволюцията на видовете. Теорията за равновесието приема, че еволюционните промени в организациите обикновено се осъществяват посредством два различни начина: а) външни шокове, които причиняват резки мутации и б) бавно и развиващи се промени, които се натрупват и в крайна сметка достигат границата-праг. Приемаме това становище на основата на теорията за равновесието с известни резерви относно външните промени, които не винаги са шокови - напр. някои законодателни промени не са внезапни (като забраната за тютюнопушенето), тъй като дълго преди тяхното въвеждане се коментират в медиите и публичното пространство.

Аналогично, за кризи може да се мисли и в ситуациите, в които жизнеспособността на предприятието е застрашена поради сериозни несъответствия между дейността и средата. Необходими са действия, за да се върне организацията обратно в равновесното си положение. От тая гледна точка организациите са обект на два вида кризи, разглеждани в динамичната перспектива: резки и кумулативни. Докато резките кризи идват с бързи сили, които внезапно вадят организациите от равновесие, кумулативните кризи набират скорост бавно, въпреки че в крайна сметка се появяват.

Всички тези подходи допринасят за обогатяване на нашето разбиране за организационните кризи.

В този аспект, можем да обобщим изследваните тълкувания за организационна криза (Зафирова, 2014) - ,това е поява на драматични явления и процеси във външната и/или вътрешната среда на организацията, имаци пряко или непряко въздействие върху нея, когато използваните до този момент методи на управление стават неефективни и нарушават жсизнеспособността й”. На тази основа, за оцеляването в условия на криза, връщането към нормалното функциониране на системата и по-нататьшното й развитие, е нужна промяна в управлението и в организацията като цяло.

Обикновено кризите се развиват циклично, понякога разрешаването на една криза води до началото на друга. Ето затова е важно решението, което ще бъде взето за изхода от кризата - то трябва да бъде стратегическо и поради това, че всяка кризисна ситуация е свързана с верига от негативни събития, които трябва да бъдат преодолени.

Най-старият и най-често цитиран в областта на организационните кризи е дейностният подход на Fink (1986), който определя следните етапи на жизнения им цикъл:

Първи етап. Предварителна фаза - симптоматика: започват да се появяват следи или нотки на потенциална криза.

Втори етап. Остра криза - кризисна атака или пронизителност (острота): събитие, което възниква заедно с придружаващи вреди. 
Трети етап. Хронична фаза: въздействието на кризата задържа усилията за излизането от нея.

Четвърти етап. Разрешение на кризата/резолюция (решение): има някакъв ясен сигнал, че кризата вече не е проблем за заинтересованите страни и вече е свършила.

Той разделя кризисното събитие на фази, които на практика са след появяването на симптомите. „Кризата започва с предизвикване на събитие (острата фаза), извършват се продължителни усилия за справяне с кризата (хронична фаза), и завършва, ясен край (решение). На различни етапи от жизнения й цикъл изисква различни действия от кризисния мениджър. Като резултат кризисното управление е въведено поетапно и поради това не е едно просто действие".

Ho Fink не определя алтернативите в последния етап. Няколко години по-късно, в следващото преработено издание на монографията си (2000), той доразвива своята концепция, като още по-точно преформулира етапите в следните: симптоми на кризата, изостряне на кризата, хронична криза и преодоляване на кризата.

Smith (1990) също посочва 4 етапа на кризата, които не се различават сьществено от тези на Fink - начало, кулминация, повратна точка и завършек (край). Това обяснение с етапите на драматично произведение, показва характера на кризите. Тук се посочва един нов термин - „повратна точка”, които някои учени заменят с „критична точка”. С него се цели да се обясни моментът, в който кризата е навлязла в период, в който организацията е на границата на ликвидността и повече не може да има грешни ходове.

Mitroff (1994) предлага друга класификация, разделяйки етапите на пет:

Пьрви етап. Откриване на симптоми - предупредителни сигнали и опити за предпазване.

Втори етап. Проучване и превенция (предпазване) - търсене на рискови фактори и намаляване на потенциалните вреди.

Трети етап. Ограничаване на щетите - предпазване от увеличение на застрашените области.

Четвърти етап. Възстановяване (оздравяване) - възвръщане към нормалната дейност най-скоро.

Пети етап. Изучаване (опознаване) - преглед и критика на мениджърските усилия за подобрения.

Съществената разлика между двата модела се намира в последния етап. Докато Fink се концентрира върху развитието на кризите, Mitroff акцентира не само върху него, но и върху усилията на ръководството, т.е. върху тяхното управление.

Подкрепяме твърдението на Darling, Seristo \& Gabrielsson (2005), че „не всички кризи имат и четирите посочени кризисни етапи (от Fink - бел. авт.), но всеки от тях е много обичаен за всяка голяма криза". Причината е, че третият и четвъртият етап могат да не се развият във всяка организация.

Coombs (2007) обяснява, че моделите на Mitroff (1994) и Fink (1986) се вписват в един интегриран тристепенен модел, като определя три етапа на жизнения цикъл на кризата, също на основата на управлението на дейностите:

- Precrisis: Кризисен инкубационен период, когато поредица от предупредителни сигнали предхождат кризата.

- Crisis (кризисно събитие): Поредица от събития, водещи към нестабилност или критични моменти, в които решително е настъпила промяната.

- Postcrisis: Период, в който нивото на безопасност е възстановено, започнали са обучение и приемственост.

Тази класификация на етапите на жизнения цикъл на кризите е основата на много изследвания в областта на управлението им. В литературните източници се посочва, че тя е уникална с това, че нито един учен не стои зад нейното създаване, но е резултат на много 
творчески тьрсения на изследователите в областта. Нашето становище е, че третият етап трябва да остане с наименованието „следкризисен”, но трябва да има включена и алтернатива за негативен изход от кризата.

Както Coombs (2007), така и Seeger, Sellnow \& Ulmer (2003) посочват, че трите етапа осигуряват рамка за включването на различните подетапи, които се променят в зависимост от множество променливи в конкретната организация. Нашето становище е, че този модел на жизнения цикъл на кризите наистина би могъл да служи като основа за изследване на кризисните етапи, но подетапите зависят от много фактори като мащаба на кризата, последствията, размера на организацията и нейната дейност и т.н.

Dubrovski (2007) повтаря етапите на Coombs, но 3-тият, следкризисния го разделя на две - оздравителен и разрешаване на кризата, с което поставя акцентьт върху него, обосновавайки по-голямата му продължителност. Това означава, че както и в посочените етапи, отново изходът от кризата е позитивен.

За разлика от тях, съществуват и такива, според които изходът е винаги негативен например фалит, както посочва Evseev (1999). Той приема трите етапа на Coombs, но предлага да се разшири представата за кризисна ситуация и да се разграничат понятията „криза" и ,неплатежоспособност (несъстоятелност)”.

Описаната от него концепция включва идентификация на кризисната ситуация с цел адекватно реагиране на негативните тенденции в условията, когато организацията още е напълно под контрола на собствениците и се управлява от наети от тях мениджъри, а следователно има все още голяма свобода на действие и по-голям избор на кризисни процедури в сравнение с обхвата дейности, осъществявани в процеса на законодателното кризисно регулиране.

Кризисната ситуация, според Evseev (1999), може да се характеризира като неефективно управление на активите и кредитните задължения на организацията, което води до отлив на парични средства от собствениците и в крайна сметка води до непълно удовлетворяване на исканията на кредиторите. Тази дефиниция свързва пряко кризата като събитие с финансовото състояние на организацията, но не отчита другите й форми, което е недостатьк на неговите изследвания.

Нашето разбиране е, че финансовата криза е последица от управленската криза. Поради тази причина считаме, че класификацията на Coombs може да се приеме за основна, като в процеса на изследване тя може да се детайлизира съобразно конкретните условия и съобразявайки я с тази на Mitroff.

Един различен модел на етапите на жизнения цикъл на организационната криза, но имащ също ендогенен характер, е разработен от друга група руски учени (Zharkovskaya, E.P., Brodskiy, 2007):

Пьрви етап. Спад - снижение на показателите, характеризиращи резултатите от дейността на организацията, в резултат на действието на външните фактори. причини.

Втори етап. По-нататьшно влошаване на резултатите под влияние на вътрешни

Трети етап. Депресия - приспособяване на организацията към новите условия на работа при по-ниски нива на приходи (при условие, че са взети първите антикризисни мерки).

Четвърти етап. Възстановяване на финансовото равновесие, оживление на производството и продажбите до предкризисното ниво.

Пети етап. Ръст на производството и продажбите, ускорено икономическо развитие в краткосрочен план.

Шести етап. Поддържане на ново икономическо ниво на развитие на организацията, устойчивост в дългосрочна перспектива, създаване на условия за рентабилност. 
Въпреки че, някои от руските изследователи се основават на тази класификация на Жарковская и Бродский, изтьквайки предимствата й от гледна точка на тяхната среда, ние не считаме, че тя трябва да се прилага като основна в изследването на кризите. Една от причините е, че при нея няма алтернатива - негативен изход, който е често срещан в практиката. Това не означава, че не трябва да се взема предвид при кризисни ситуации, водещи до несъстоятелност.

Не бива да се пренебрегва фактьт, че все пак голяма част от руските учени в областта, се позовават на основните три стадия на развитие на кризата, посочени от Cooms, въпреки другите им наименования (Ivasenko, Nikonova и Karkavin, 2011 и др.):

Ранна, характеризираща се с отделни проявления на неефективност в производството, снабдяването (ръст на стоково-материалните запаси, снижение на темпа на ръста на продажбите, проблеми с качеството на продукцията и др.).

Промеждутъчна - недостиг на оборотни средства, прекратяване на плащанията по кредитите, задържане на плащанията на работните заплати.

Късна, при която организацията се намира в състояние на хаос, нарушавайки графика на производство, кредиторите изискват изменения на условията на кредитите, а доставчиците - предплащане.

С. Савов, позовавайки се на някои от посочените западни и руски учени, дефинира 4 етапа на кризата в едно изследване на учени икономисти (), на основата също на ендогенния подход (Iliev, Y. (red.), 2011):

Латентен (скрит) - назряване на кризата, има симптоми, но те все още не се проявяват напълно.

Срив - бързо обостряне на противоречията, в резултат на което се влошават показателите. Появяват се елементите на нова система, представляваща основата на бъдещия цикъл. Те набират сили и встъпват в борба с елементите на старата система. Нарушава се устойчивостта.

Смекчаване на кризата - на този етап се създават предпоставки за преодоляване на кризата, преход към фазата на депресията, осигуряващ временно равновесие между загубилата своята сила система и утвърждаващата се нова такава, която е в основата на новия цикъл.

Излизане от кризата - Край на кризата. Остарелите елементи губят своята сила, отмират, а тяхното място се заема от елементите на новата система. Възможни последствия от кризата са разрушаване или обновяване на организацията, изостряне или изглаждане на противоречията, оздравяване или задълбочаване на кризата.

Савов повтаря някои от вече посочените модели на жизнен цикъл на кризата - на Fink и др. Разликата е в разделянето на някои от етапите. Освен това, той посочва пообстоятелствено какво се случва в самата организация от гледна точка на системния подход, но не така задълбочено и описателно, както това прави Bogdanov (1989) в неговата тектология.

Интерес представляват и етапите на един друг релационен модел на австралийския учен Jaques (2007), международно признат експерт в областта на управлението на кризи. Моделът се основава на клъстери и форми на нелинейни елементи и е създаден доста покъсно (2007) от този на екипа на Mitroff (1987), но все пак преди световната финансова и икономическа криза. Този нов модел се основава на една цялостна представа за управлението на кризи, че предотвратяване на кризата и подготовка за кризи са част от цялостния процес на управление на кризите като стьпки, които трябва да се предприемат, след като се зададе кризата. Jaques (2007) твърди в резултат на своите изследвания, че в много случаи тези два етапа се сливат. Поради тази причина, той обособява следните етапи, като детайлизира действията в тях: 
А. Подготовка за кризи.

Б. Превенция (предотвратяване) на кризи.

В. Управление на кризисни ситуации.

Г. Следкризисно управление.

След края на всяка криза логично се появява желанието да се премине възможно найбързо към следващ етап, за да възобнови дейността си. И се разработват бизнес програми за възстановяване, които се фокусират върху инфраструктурни, персонални и други подобни промени. Stocker (1997) посочва, че „потенциалът за съдебни разходи показва и определя до колко организацията реагира на кризата, но в почти всички случаи, това накрая завършва като малък дял от крайните разходи”. Според него, най-големият сегмент на пазарните разходи - нереализираните продажби, загубите от продукти и услуги и увредената репутация се отразяват на пазарния дял, на способността на организацията да расте, и на маржовете, като в същото време пазарната й стойност „страда” като цената на акциите падат.

Интерес за нашето изследване представлява разделението на Jaques (2007) на следкризисното управление на три подетапа.

„Г1. Следкризисно управление - оздравяване, възобновяване на дейността

Включва възстановяване на оперативната дейност, финансови разходи, задържане на пазара, бизнес инерция, защитата на цената на акциите. кризата

Г2. Следкризисно управление - следкризисни резултати от въздействията на

Включва следствени дела, съдебни разследвания, прокурорски проверки, съдебни спорове, увредена репутация, внимание на медиите.

ГЗ. Следкризисно управление - оценка, промяна

Включва анализ на първопричините, оценка на управлението, процес на преразглеждане, осьществяване на промяната.“

Jaques посочва в своя релационен модел, че докато обучението и оценката следва да се извършват на всеки етап на релационния модел, следкризисната фаза предлага особено добри условия за истинско корпоративно обучение и системи за модификация.

Краят на всяка криза трябва да бъде началото на подготвителната стъпка за следващия етап - и Penrose (2000) твърди, че организациите, които успяват да оцелеят от кризи и бедствия са по-подготвени за бъдещи предизвикателства. Въпреки, че Fink (1986), позовавайки се на проучване на Fortune 500, е установил, че от тези организации, които съобщават, че са имали криза в миналото, $42 \%$ все още нямат какъвто и да е План за управление на кризи.

Kuzmanova (2016) обръща специално внимание на управление на промяната в следкризисния етап, като описва технологията на този процес. Nikolaeva, V. (2018) го свързва с процеса на стратегическо управление, а в Panayotova, G., Dimitrov, G., Petrov, P., Bychkov, O. (2016) можем да открием вариант на моделирането му в информационна система за обработка на данни. Тази колаборация ще помогне на мениджмънта на предприятията в търсене на оптимизация на процеса на вземане на правилни управленски решения.

\section{2. Правни аспекти на стабилизиране на предприятията след криза}

В зависимост от целите и правно охраняемия интерес, насочени към защита правата на кредиторите или длъжника, в отделните държави са установени два основни законодателни подхода при регламентиране института на несъстоятелността. Във Великобритания нормативната уредба е ориентирана към защита интересите на кредиторите, а във Франция, САЩ и Япония е насочена в превес към защита правата на длъжниците и на работниците.

C особена актуалност в световен мащаб са законодателните подходи за регламентиране на процедури, които да предоставят ефективен механизъм за стабилизиране 
на предприятията при наличието на застрашаваща неплатежоспособност. Те са в тясна връзка с концепцията за fresh start, утвърдена в САЩ (Porter, 2008). В съвременните условия развитието на законодателствата в тази сфера (Report from the Commission to the European Parliament, 2012) показва тенденция към регламентиране на производства извън производствата по несъстоятелност, които представляват квазиколективни и/или хибридни производства. В тази връзка е актуализирана нормативната уредба в Австрия, Белгия, Естония, Франция, Германия, Гърция, Латвия, Малта, Нидерландия, Италия, Полша, Румъния, Испания, Швеция, Обединеното кралство. Като част от цялостния процес е и България, която през 2016 година прие в Търговския закон (Т3) правна уредба на специално производство по стабилизация на търговеца. То е сходно с утвърдените производства в европейските законодателства, поради правото на длъжника да реши финансовите си затруднения на основата на споразумение с кредиторите и по този начин да предотврати съдебната процедура по несъстоятелност.

Въз основа на нормативния анализ на отделните законодателства се констатира, че в Германия, Франция, Англия и САЩ са уредени производства, при които длъжникът при наличие на застрашаваща неплатежоспособност има право да приложи мерки за преструктуриране на предприятието си преди откриване на производство по несъстоятелност (Melehova, 2012). В Германия с приемането на Закон за последващо улесняване на преструктурирането на компаниите ( ESUG) се въвежда специално производство по защита, в което длъжникът предлага план за саниране на предприятието. Характерно за законодателството на Франция е наличието на нормативни условия за ранното оздравяване на длъжника чрез въвеждането на: а) предохранителна процедура по производство за защита и б) помирителна процедура.

Особеностите на производството по защита се отнасят до основанието за откриване му и правомощията на компетентния орган. Активно легитимиран да открие производството е единствено и само длъжникът при наличие на убедителни писмени доказателства, от които може да се направи обоснован извод за бъдещо спиране на плащанията. Производството се развива пред съда по несъстоятелността, който оказва непосредствен контрол върху дейността на търговеца. При основателност на молбата, с решението си съдът поставя началото на период за наблюдение до 6 месеца, в рамките на които длъжникът може да вземе мерки за съхраняване на дейността си. Предназначението на контрола от страна на съда е: да не се извърши неправомерно намаляване на имуществото му и неговите активи. Съдът разполага с правото служебно да преобразува производството по защита в производство по несъстоятелност, когато целите на защитното производство не са постигнати.

При помирителната процедура във френското право основанието за откриване на производството е: спирането на плащанията да не е продължило повече от 45 дни. Активно легитимиран да предяви иск е само длъжникът. Основната цел е да се сключи споразумение с кредиторите за преодоляване на финансовите затруднения. Споразумението подлежи на утвърждаване от съда, в резултат на което и производството се прекратява.

В американското право се допуска сключване на извънсъдебното споразумение преди същинското производство по несьстоятелност. То придобива задължителен характер, освен за кредиторите, които са изразили несъгласие. За разлика от Франция и Германия, за приемането му не изисква участие на съда. Компетентният съд открива съдебно производство при наличие на нормативните предпоставки за него, само при условие че отсъстват основания за финансово оздравяване на предприятието или възможност за външно управление.

В България производството по стабилизация на търговеца притежава идентична цел c разгледаните производства в отделните държави. Като научна критика към него е сходството му с производството по оздравяване на предприятието, уредено от ТЗ в рамките на съдебната процедура и предоставеното право на съда да изземе управлението от търговеца 
и да го възложи на „доверено лице“1. Възможността да се лиши длъжника от управление на неговото имущество преди настьпването на реална неплатежоспособност се явява сериозна бариера за прилагането на производството в практиката. Като положителна страна на правната ни уредба е приближаването й към законодателствата на развитите държави и създаване на юридически регламент за предоляване на финансовите затруднения на ранен етап.

Следователно, специфичното в съвременната правна регулация е, че под надзора на съда или административен орган се предоставя възможност на длъжник - търговец да осъществи оздравяване на етап, предшестващ производството по несъстоятелност. При хибридните производства особеното е, че длъжникът запазва известен контрол върху активите и дейността си, независимо от надзора на компетентния орган. Основната тенденция в нормативната уредба на отделните държави е въвеждането на защитни процедури, които предоставят на търговеца време и средства да преструктурира предприятието си с цел избягване на неплатежоспособността. Те се характеризират с многообразие като правна характеристика и същност. Обединяваща е тяхната цел, насочена към съхраняване на предприятието на длъжника с подходящи правни средства.

\section{Заключение}

От направеното проучване на теоретичните изследвания за следкризисния етап в управлението на предприятията, възможните алтернативи от него и правните модели в различните държави в съответствие с техните законодателства, могат да се направят следните изводи и обобщения:

- В специализираната литература съществуват няколко основни концепции за жизнения цикъл на кризите. Разликата в тях се състои в това дали обхващат самата кризисна ситуация или/и времето преди нея (симптомите) и след нея (система за превенция срещу кризите).

- Основната и най-често срещана концепция, както и нейни модификации, в литературните източници е представената от Coombs: предкризисен етап - кризисен етап следкризисен етап. Тя е основа за разработване на подетапи в зависимост от конкретната кризисна ситуация, които се определят от формата й на проявление, мащаба и продължителността й.

- В някои от концепциите за жизнения цикъл на кризите, не съществува негативен вариант в последния етап, което е често срещано явление, т.е. те разглеждат само положителен изход от кризата. Тези концепции са предпочитани от практиката, но не са реални.

- Проучването на изследванията на различни учени в областта на управлението на кризи на предприятията, правната среда и практиката в различни държави показа, че тенденцията в развитието на нормативната уредба в отделните законодателства е към прилагане на оздравителната (реабилитационна) процедура с предимство пред ликвидационната процедура, с което се цели и възстановяване на тяхната платежоспособност.

\section{References}

1. Bogdanov, A. (1989) Tektologiya (Vseobshtaya organizatsionnaya nauka). Moskva: Ekonomika, kn.1.

2. Coombs, W. T. (2007) Ongoing Crisis Communication: Planning, Managing and Responding, (2nd ed.), SAGE.

3. Dubrovski, Dr. (2007) Management Mistakes as Causes of Corporate Crises: Countries in

\footnotetext{
1 Довереното лице, се определя от съда и осъществява надзор върху дейността на търговеца в производството по стабилизация.
} 
Transition. Managing Global Transitions, (5) 4, pp. 333-354.

4. Evseev, A. (1999) Strategiya restrukturizatsii predpriyatiy v usloviyah krizisnoy situatsii. Problemay teorii i praktiki upravleniya, 3.

5. Fink, St. (1986) Crisis Management: Planning for the Inevitable. NY: Blackprint.

6. Hwang, P., Lichtenthal, J. D. (1999) Anatomy of Organizational Crises. The Pennsylvania State University, ISBM Report 28-1999.

7. Jaques, T. (2007) Issue Management and Crisis Management: An Integrated, Non-linear, Relational Construct. Public Relations Review, 33 (2), pp. 147-157.

8. Ivasenko, A.G., Nikonova, Ya. I., M.V. Karkavin (2011) Antikrizisnoe upravlenie. (2-oe izd.), Moskva: KNORUS, 2011.

9. Iliev, Y. (red.) (2011) Antikrizisno upravlenie na industrialnite firmi. Sofiya: Avangard Prima.

10. Kuzmanova, M. (2016) Conteporary problems related to crisis management of organizations. Trakia Journal of Sciences, 3, pp.256-261.

11. Melehova T.W. (2012) Practice financial recovery of enterprises in Russia and abroad, [Online] Available at: http://orelgiet.ru/docs/nauchzap/44-melehova.pdf

12. Mitroff, I. I. (1994) Crisis Management and Environmentalism: A Natural Fit. California Management Review, 36 (2), pp.101-113.

13. Nikolaeva, V. (2018) Strategic management of business organizations - opportunities and challenges. Izvestia Journal of the Union of Scientists - Varna. Economic Sciences Series, 7 (3), pp.221-230.

14. Panayotova, G., Dimitrov, G., Petrov, P., Bychkov, O. (2016) Modeling and data processing of information systems. 3rd International Conference on Artificial Intelligence and Pattern Recognition (AIPR), Lodz, Poland, IEEE, pp.154-158.

15. Penrose, J.M. (2000) The Role of Perception in Crisis Planning. Public Relations Review, 26 (2), pp.155-171.

16. Porter, K., Thorne, D. (2008) The failure of bankrupty`s fresh start. Cornell Law Review, 92 (67), [Online] Available at: http://www.lawschool.cornell.edu/research/cornell-lawreview/upload/ porterthorne_92-1.pdf

17. Report from the Commission to the European Parliament, the Council and the European Economic and Social Committee - on the Application of Council Regulation (EC) No1346/2000 of 29 May 2000 on Insolvency Proceedings, (2012) [Online] Available at: http://ec.europa.eu/justice/civil/document/index_en.htm

18. Seeger, M.W., Sellnow, T.L., Ulmer, R.R. (2003) Communication and Organizational Crisis. Westport, CT: Praeger.

19. Smith, D. (2006) Key Readings in Crisis Management. Elliott. London: Routledge.

20. Stocker, K. (1997) A Strategic Approach to Crisis Management. In: C.L. Caywood (Ed.) The Handbook of Strategic Public Relations and Integrated Communications. (pp. 189-203) New York: McGraw-Hill.

21. Zafirova, Tz., Yordanova, M. (2016) Recovery of Company Management in the Postcrisis Stage - Opportunities and Legal Models. Journal L'Association 1901 „SEPIKE”, Social Educational Project of Improving Knowledge in Economics, 13, pp.135-139.

22. Zafirova, Tz. (2014) Strategic Aspects in Organizational Crisis Management. Science and Economics.

23. Zharkovskaya, E.P., Brodskiy, B.E. (2007) Antikrizisnoe upravlenie. Moskva: OMEGA-L 